\title{
The Power of Verbal and
}

\section{Nonverbal Communication in Learning}

\author{
Akhtim Wahyuni \\ Magister Manajemen Pendidikan Islam \\ Universitas Muhammadiyah Sidoarjo \\ Sidoarjo, Indonesia \\ awahyuni@umsida.ac.id
}

\begin{abstract}
Teaching and learning activities involve communication between teachers and students, both verbal and nonverbal. These communications are interrelated in learning practice. The teacher ability in applying both can help improve the quality of learning in the class. It has an impact on the academic and non-academic performance of students. Instead, if the teachers are not able to communicate effectively in transferring knowledge, skills, and attitudes, it will be hard to achieve the expected objectives. This shows that students who understand and can do the tasks very well also depend on how the teachers' style of verbal and nonverbal communication. Verbal communication includes short talk, discussion, jokes, ideas, and so forth. Nonverbal communication skills include body language, the use of the eye contact, the distance stands with the students, touch, and hearing. Then the two communication skills must always honed by teachers, to create a quality learning.
\end{abstract}

Keywords-communication; verbal; nonverbal; learning

\section{INTRODUCTION}

As social creatures, humans need to collaborate with others to live, develop, and act. However, communication conflict often hampers people to develop their social relationship. It can cause many feelings such as lonely, worthless, and isolated. Further, it leads to depression, stress, and lose the meaningfulness of life. Everyone needs someone else to fulfill its social needs. From the social interaction they can meet the needs for attention, affection, and love. Thus, the role of friends is significant as the supportive social environment that contribute to the psychological maturity of the person. In line with this, [1] stated that social intelligence determines a person's life. Social relations is believed to give a very meaningful impact to both one's personal psychics as well as physic because social intelligence is not only defined as ' relationship person with others, yet the meaning of relationship itself. The scope of social intelligence is pushing someone to enrich the personal relationship such as empathy and caring. The real form of this social intelligence is the ability to communicate with others effectively [1]. In the process of teaching and learning, the effective communication becomes a very crucial part because that activity involves communication between students and teachers as well as other stakeholders. Therefore, verbal and nonverbal communication is an aspect that needs to be emphasized for every teacher since the teacher used the words to convey the materials to the students orally. In addition, [2] explained that sometimes teachers deliver it via gesture, the facial expressions, the contact point of view, appearance and so on.

\section{VERBAL AND NONVERBAL LEARNING}

The personality is formed throughout the life of a human being. During this time the communication becomes essential for personal growth. Through the communication people will find themselves, develop the self concept, and define the relationship with the world. Relationships with others will determine the quality of someone's life. The failure in building good communication will happen when people do not want to understand others' thoughts/ideas, feel annoyed when getting message, create further distance when communicating with others, always fail to encourage others to act [3].

Related to the teachers' teaching performance, it is highly expected that they have skill to communicate effectively because it is considered as one important determinant of teaching and learning success. Educators are not only demanded to be effective in teaching and learning activities (transfer of knowledge), but also in their personal relationships and "modeling" (transfer of attitude and values), for both the learners as well as all members of the school community [4]. Moreover, a humanist education gives more emphasis in establishing a personal relationship and communication between individuals and interpersonal and group within the school community. This relationship is evolving rapidly and bear good education if it is grounded by the love. In other words, individuals can optimally develop and relatively unhindered if it is in an full of love atmosphere (unconditional love), understanding heart as well as effective personal relationships. In educating a person, the teacher should be able to accept themselves as they are and then express it honestly (modeling). In addition to transferring knowledge, the word "educate" is supposed to train verbal skills to the learners in order that they can develop themselves optimally.

[5] agrees that verbal and nonverbal communication is a unity that cannot be separated to convey a message. Thus, in carrying out the learning process of teachers must be able to combine these two types of communication. The ability of teachers in applying them can help improve the impression in the process of teaching and learning. [6] argue that the process of memorable teaching and learning activities are the result of a communication relationship between teachers and students 
as well as the credibility of a teacher. This indicates that the relationship of teacher-student and teacher attitude toward work is crucial in improving positive behaviours.

Communication is also the manifestation of an accurate and open attitude in the information change. It is the core of creativity and keeping the school running effectively. Besides, it is very crucial in shaping teacher's social reality. Meanwhile, according to[7], the relationship of teachers and students has significant effects towards the stress level of students. The teachers who communicate effectively with students will greatly help in learning and the daily interaction. Communication is closely related to culture. Nevertheless, the culture itself can be a challenge in building interaction that potentially causes misunderstanding. Students competence depends on how the teacher can communicate with them smoothly. [4] strongly believe that communication is the dimension of the essence in creating effective education. Problem in language is a problem in understanding the language, and includes find the right words, the right voice pattern, and the right shades; It is associated with problems of hearing ability and pronunciation, speed, tone, and tune.

In America, according to[8], the pronunciation is an important factor in communicating, the use of the proper pronunciation will help students respect and confidence in teachers. In Asian countries, the phenomenon of ' saving face ' and ' losing face' 'as a form of indirect communication statement. In this condition, the students pointed out that he has already learned something when in fact it is not. This is because the student response shows those who are not familiar may reflect negatively on students and teachers. Nonverbal communication is very important because it shows the credibility and teachers' leadership [9]. There are 6 types of nonverbal communication associated with effective teaching, namely: eye contact, paralanguage, gesture, posture, clothing and environments, as well as facial expressions.

Teachers as role models for students, both inside and outside the classroom. [10] says, less positive teacher behaviors may cause some negative effects on the students. [2] stated that interaction in classes between teachers and students takes place very quickly. [11] predicts that primary school teachers interact with 150 different students each day. However, often the teachers do not give full attention or cannot explain what happened during the interaction with their students. For example, teachers usually do not care how the question was already given to the students, and how feedback is delivered. Therefore the teacher should understand that behavior and their interaction in learning can be identified and recorded.

[12] examines the behavior of the teacher in the classroom by adapting theories of communication process developed by Waltzlawick, Beavin, and Jackson (1967). With a system of communication perspective, it can be assumed that the person's behavior is influenced by the others' behavior. The teacher's behavior is also influenced by the behavior of students, then, the process of developing communication rounds. This systems approach assumes that one cannot communicate without the presence of the other. The detailed overview of verbal and nonverbal communication is presented as follows:

\section{A. The Nonverbal Communication in Learning}

Teacher quality is an important factor for student achievement. One of the qualities that should be perceived is the teachers should have good social skills so that students can communicate well with them. These social skills are required of everyone in interacting and communicating with others. There are ways of verbal and nonverbal communication. Verbal communication includes short talk, discuss, sharing jokes and ideas. For nonverbal communication includes active listening. Teachers should listen carefully to their students with great empathy. Teachers also have to hear ' the talk ' with his classmates. In addition, the body language also includes non verbal communication. This becomes an important part of communication as $50 \%$ more is used in communication. Finally, the teacher must have verbal and nonverbal communication skills with their students, to persuade, to resolve the issue, and motivate them[13].

Teachers who have good social skills will look through body and oral language. Teachers must have the ability to explain so that students clearly understand what the teacher is delivered. Therefore, this will make teaching and learning more effective. In addition, teachers who have good social skills will easily solve the problem and motivate the students. They have a social conscience, the ability to understand, and prediction to the behavior and feelings of the students. Accordingly, the social skills is one of the criteria of quality teachers.

To get data about the teacher's nonverbal behavior, [14] developed an instrument of class observation. Nonverbal behavior measured one facial expression the teacher, the student is accepted as a very important aspect to determine the level of cooperative interpersonal teacher. Other studies conducted by [15] who showed that the behavior of the teacher can give the effect on student's achievement. According to this study, the question given by the teacher and the student's answer is the main factor showing how the interaction between teachers and students occurs in the classroom.

[16] explains the concept of cooperation skills and intercultural communication skills of Pearson is the basic skills needed to help teachers, not only completing a few factors stressor that occurs on teachers but also for facing the new environment. Recently the young teachers in Pakistan give high interest to innovation and learning as well as a reflection of the importance of trying to find a nonverbal communication for teachers. Through nonverbal communication, teachers can save energy in speaking. Students can also be involved and motivated as well as obtain freedom in the process of discussion in the classroom.

Nonverbal communication is the process of sharing meaning interpretive and multi-media communication type. $\mathrm{He}$ is both natural, reliable and spontaneous. Communication plays a very significant role in interpersonal and communication is very important for a teacher to directly communicate with the students in the class. Nonverbal 
communication skills that must be mastered by teachers: body language, the use of eye contact, the distance stands with the students, touch. According to [14], in classroom management almost $75 \%$ use nonverbal.

A research shows nonverbal communication became one of the most culturally influenced by behavior. Thus, the study of nonverbal communication should be included in the curriculum of learning as the difference between a significant cultural role when members of one of the other language culture learn it [11]. For example, using nonverbal communication in learning become one of the best ways for effective English teaching for Japanese and non-Japanese people.

Awareness in using nonverbal communication contribute to the consciousness of interculture, not only with native speakers but also non-native speakers from other countries that have a different cultural background. Nonverbal communication plays an important role in human social interaction. However, the phenomenon of nonverbal communication is almost never examined. Lately a range of disciplines began to be attracted to review them. Starting from the disciplines of anthropology, economics, language, and education. It was concluded that nonverbal signals play a pivotal role in the communicative classroom.

The object of nonverbal communication is different among authors. [13] includes nonverbal communication such as body contact, posture, proximity, facial, body, physical, view movements, voice emotion while talking, mistake in speaking, accent. Meanwhile, according to [14] are physical characteristics, movement, touch, proximity, artifacts, and environmental factors.

[12] in the article 'A Nonverbal Communication Lesson' presents how to teach nonverbal communication. The techniques that can be used to teach nonverbal communication are described as follows:

- $\quad$ The learners are invited for discussion about the meaning of the gesture (gesture) and expression (demonstrated by the teacher, through images, or other material)

- The learners imitate both physically and emotions.

- The learners are invited to watch the video clip with no sound, discuss body language, relationships, emotions and feelings, then write the dialogue.

- The learners make dialog with the use of gesture and expression only.

- The learners polish dialogue based on the results of the imitating.

- The learners, in pairs, to listen to each other for 30 minutes, using only non-verbal response.

Darn explains that using effective nonverbal communication in classroom should add an extra language, namely: reducing the time of speaking, increasing the participation of students, building confidence, reducing fear for the rest, giving clear instructions, efficient classroom management, creating an atmosphere in the classroom, improving listening skills, improving performance activities in pairs or groups, mutual friends and self correction, avoiding misunderstandings, and enhancing intercultural competence.
The teacher should always remember that gesture and other nonverbal communication need to be taught in the classroom. Make sure that students understand the symbols and know how to use them.

\section{B. Verbal communication in Learning}

The teacher is the one who always provides an explanation in the class. Good teachers are teachers who become role models in speaking and have good writing skills. Teachers are also required to understand the students ' verbal communication and are able to help students improve their verbal ability. [8] mentions that verbal ability refers to one's skills to make use of ideas through words, either oral or written. These skills involve vocabulary mastery to be able to choose the right words to give meaning to the audience. Verbal ability also concerns the ability to organize the words in a way that is logical. Verbal ability is part of a traditional construction intelligence.

- In General, the verbal abilities of the teachers are:

- Clear in explaining information

- Give obvious explanation

- Help students to use the ideas in words

- Help students improve their communication skills

- Help students understand the meaning of the written language

- Capable of using analogies in learning

- Communicate well with parents either orally or written

- Communicate effectively with personnel administration.

\section{CONCLUSION}

Communication skills are very important for the one's future, the quality of life, and success. Teachers' verbal and nonverbal communication have a major role in supporting the educational success. Teachers who understand the importance of this communication will be able to become qualified educators and create meaningful learning. For that reason, teachers should do that with extra effort by doing positive communication involving verbal and nonverbal communication. Finnaly, communication in education is a specific communication being done specifically so that the teacher is able to understand the students and the entire school community.

\section{ACKNOWLEDGEMENT}

I would especially like to thank Universitas Muhammadiyah Sidoarjo for the support so that this paper can be accomplished.

\section{REFERENCES}

G. Daniel. Social Intelligence, The New of Science of Human Relationship. New York: Random House USA Inc. 2006.

D.M. Kenneth. Classroom Teaching Skill. Edisi ke-6, Mc Graw Hill. 2007. 
[3] Norliza, AM. et al. Communication Skills and Work Motivation Amongst Expert Teachers, Procedia Social and Behavioral Sciences, 7C , pp. 565-567. 2010

[4] F. Domenech \& A. Gomez. The relationship among students' and teachers' thinking styles, psychological needs and motivation In Learning and Individual Differences 29, pp. 89-97. 2014.

[5] R.J.M. García. Communication, key to visible excellence in Higher Education. Journal for Educators, Teachers and Trainers, 3, $25-$ 36. 2012.

[6] L. Pogue \& K. Ahyun. The Effect of Teacher Nonverbal Immediacy and Credibility on Student Motivation and Affective Learning, Journal Communication Education Volume 55, Issue 3. P. 331-344. 2006.

[7] D. Jackson. Business graduate performance in oral communication skils and Strategies for improvement. The International Journal of Management Education, 12, 22-34. 2014.

[8] Andrew, et.al. Verbal Ability and Teacher Effectiveness, Journal of Teacher Education. 2005.

[9] S. Ronald \& I. Fajlik. Introducing non verbal Communication to Japanese University Students: Determining Content, Univ; Japan. Journal of Intercultural Communication. 2007.
[10] L. Wolfgang. Nonverbal aspects of Teacher-Pupil Communication in the Foreign Language Classroom, University of Leipzig Germany. 2002.

[11] D.G. Morine. Talking, listening, and learning in elementary classrooms. New York: Longman. 1985.

[12] D. Eryilmaz \& S. Darn. A Non Verbal Communication Lesson, Izmir University of Economics. 2005.

[13] P.L. Witt \& R.L. Wheeless. An experimental study of teachers'verbal and nonverbal immediacy and students' affective and cognitive learning, Journal Communication Education, Vol. 50. p. 327-342. 2001.

[14] S. Darn. Aspects of Nonverbal Communication, The Internet TESL Journal, Vol.XI, No.2. 2005.

[15] M.H. Tariq. Non Verbal Communication: The Language of Motivation for Pakistani Students, , Jurnal Language in India, volume 7. 2007.

[16] B. Gulkekin. Dialog and Mediation Education in Intercultural Communication. Procedia Social and Behavioral Sciences, 55, 1124-1133. 2012. 